\title{
INFLUÊNCIA DOS ENCONTROS MUSICAIS NO PROCESSO TERAPÊUTICO DE SISTEMAS FAMILIARES NA QUIMIOTERAPIA ${ }^{1}$
}

\author{
Leila Brito Bergold², Neide Aparecida Titonelli Alvim ${ }^{3}$
}

\footnotetext{
${ }^{1}$ Extraído da tese - Encontros musicais: uma estratégia de cuidado de enfermagem junto a sistemas familiares no contexto da quimioterapia, apresentada ao Programa de Pós-Graduação da Escola de Enfermagem Anna Nery (EEAN) da Universidade Federal do Rio de Janeiro (UFRJ), 2009.

${ }^{2}$ Doutora em Enfermagem. Chefe do serviço de Musicoterapia do Hospital Central do Exército. Rio de Janeiro, Brasil. E-mail: leilabergold@terra.com.br

${ }^{3}$ Doutora em Enfermagem. Professora Associado do Departamento de Enfermagem Fundamental da EEAN/UFRJ. Rio de Janeiro, Brasil. E-mail: titonelli@globo.com
}

RESUMO: Este estudo investigou a influência da música e das narrativas no processo terapêutico de sistemas familiares participantes de Encontros Musicais durante a quimioterapia. Pesquisa Convergente-Assistencial, realizada em um hospital militar na cidade do Rio de Janeiro com 27 sujeitos, entre clientes e familiares, tendo sido realizados oito encontros no total. Os resultados, fundamentados na avaliação dos Encontros Musicais pelos próprios sujeitos, apontaram a influência da música no processo terapêutico, ao proporcionar distração, descontração e relaxamento, promovendo acolhimento e interação grupal. Apontaram também a influência das narrativas ao produzir conhecimento grupal e estimular a expressão de experiências sobre o adoecimento e suas repercussões nas relações familiares, desenvolvendo uma rede de apoio.

DESCRITORES: Enfermagem oncológica. Musicoterapia. Quimioterapia. Relações profissional-família.

\section{THE INFLUENCE OF MUSICAL ENCOUNTERS IN THERAPEUTIC PROCESS OF FAMILY SYSTEMS IN CHEMOTHERAPY}

\begin{abstract}
This paper investigated the implementation of music and narratives as a therapeutic care strategy for family systems participating in the Musical Encounters group during chemotherapy. We opted for Converging-Care Research, carried out at a military hospital in Rio de Janeiro involving 27 subjects, including clients and family meeting in a total of eight Musical Encounters. The results, based on the assessment of Musical Encounters by the subjects themselves, showed that the influence of music in the therapeutic process provides distraction and relaxation, as well as promotes acceptance and group interaction. They also pointed to the influence of narratives in producing group knowledge and stimulating the expression of experiences about the illness and its impact on family relationships, thus developing a support network.
\end{abstract}

DESCRIPTORS: Oncologic nursing. Music therapy. Drug therapy. Professional-family relations.

\section{LA INFLUENCIA DE LOS ENCUENTROS MUSICALES EN EL PROCESO TERAPÉUTICO DE LOS SISTEMAS FAMILIARES EN LA QUIMIOTERAPIA}

RESUMEN: Este estudio se investigó la influencia de la música y las narrativas en el proceso terapéutico de los sistemas familiares que participan en los Encuentros musicales durante la quimioterapia. Es una investigación Convergente Asistencial, realizada en un hospital militar en Rio de Janeiro con 27 sujetos, incluidos los clientes y la familia, después de haber llevado a cabo un total de ocho Encuentros Musicales. Los resultados, basados en la evaluación de los Encuentros Musicales por los propios sujetos, mostraron la influencia de la música en el proceso terapéutico para proporcionar distracción y la relajación, la promoción de la aceptación y la interacción del grupo. También indicaron la influencia de las narrativas en la producción de conocimiento grupal y estímulo para la expresión de experiencias sobre la enfermedad y su impacto en las relaciones familiares, y el desarrollo de una red de apoyo.

DESCRIPTORES: Enfermería oncológica. Musicoterapia. Quimioterapia. Relaciones profesional-familia. 


\section{INTRODUÇÃO}

Com o envelhecimento da população, o câncer se transformou em um problema de saúde pública no Brasil. O Ministério da Saúde aponta a necessidade de se garantir acesso aos serviços e cuidado integral na área de oncologia, no entanto, dá pouco espaço à família, referindo-se a 'apoio familiar/suporte social'. ${ }^{1}$ A assistência em oncologia, apesar de apontar a importância de uma abordagem psicossocial ao cliente e seu familiar, ainda se volta prioritariamente para uma prática tecnificada, havendo a necessidade de maior produção de vínculo e acolhimento no cuidado. ${ }^{2}$

Nesse contexto, torna-se importante desenvolver atividades voltadas para o cuidado integral a clientes e familiares, com a finalidade de atender às necessidades surgidas a partir do momento do diagnóstico de câncer e que prosseguem no decorrer do tratamento de quimioterapia, pois esta também traz sofrimento ao familiar devido às alterações emocionais e físicas, além de mudanças no cotidiano. ${ }^{3}$

Assim, deve-se ter a perspectiva da família como um sistema, visto que toda vivência interfere com o seu funcionamento. ${ }^{4}$ Destacam-se aqui as dificuldades enfrentadas pelo sistema familiar, ampliadas pelas expectativas de morte e perdas relacionadas ao câncer e à quimioterapia. Nesse enfoque, importa pensar em estratégias terapêuticas que possam promover a assistência integral aos envolvidos, abrangendo os aspectos psicossociais, além dos cuidados técnicos.

Outro aspecto que se destaca é o número reduzido de publicações que enfocam propostas inovadoras de assistência de enfermagem voltada para o apoio psicossocial ao sistema familiar que (con)vive com o câncer, em especial, com o uso de música. Com o intuito de pesquisar uma intervenção que pudesse ampliar os recursos terapêuticos na assistência de enfermagem em oncologia, foram desenvolvidos Encontros Musicais (EMs), como uma estratégia que alia música à atividade grupal multifamiliar, buscando promover bem estar e o diálogo entre os participantes, e entre estes e a enfermeira.

Dessa forma, este estudo apresenta parte de uma tese de doutorado que investigou a implementação dos Encontros Musicais, como estratégia de cuidado grupal, junto a sistemas familiares no contexto da quimioterapia. ${ }^{5}$ Os objetivos desse estudo são: caracterizar a influência da música e das narrativas no processo terapêutico dos sistemas familiares participantes dos encontros musicais; e conhecer a pertinência dos encontros musicais na perspectiva dos sistemas familiares deles participantes.
Para subsidiar o desenvolvimento dos EMs, buscou-se aproximar os conhecimentos do campo da enfermagem e da musicoterapia, através de abordagem transdisciplinar, amparada pela visão sistêmica do paradigma da complexidade. Essa visão evita a separação do biológico, do psicológico e cultural, ampliando o enfoque no contexto familiar e social. ${ }^{6}$

O Caritas Processes de Jean Watson é uma ampliação dos Fatores de Cuidado, sendo uma atualização de sua filosofia/teoria, e por sua abrangência, proporciona o fundamento teórico necessário ao cuidado expressivo ao cliente e seu familiar, no contexto da quimioterapia. Esse processo aponta a importância de se desenvolver um ambiente propício para a reconstituição em todos os níveis, desenvolvendo uma relação de ajuda-confiança, em que os participantes possam se expressar, construindo uma genuína experiência de ensinar e aprender. ${ }^{7}$

As relações desenvolvidas entre música, saúde e cultura sustentam a utilização da música com finalidades terapêuticas, considerando a influência desta no contexto cultural dos sujeitos, e relacionando-a a eventos significativos de sua vida. Reviver lembranças através do estímulo musical facilita a expressão de sentimentos e narrativas de vivências, não só relacionadas ao adoecimento, mas às experiências de vida. ${ }^{8}$

\section{METODOLOGIA}

Como a finalidade do estudo voltava-se para a implementação dos Encontros Musicais, optou-se pela Pesquisa Convergente-Assistencial (PCA), por esta aproximar a pesquisa da assistência, mantendo o compromisso de beneficiar tanto o contexto assistencial quanto a pesquisa, com as informações procedentes desse contexto. ${ }^{9}$ Essa metodologia também tem sido utilizada por outros estudos voltados para clientes portadores de doenças crônicas, e mostrou seu potencial na mudança de estilos de vida e na realidade da vida dessas pessoas, através do diálogo entre o campo da prática assistencial e da própria investigação científica. ${ }^{10}$

A pesquisa seguiu as etapas da PCA, sendo utilizadas as seguintes técnicas para a produção de dados: entrevistas com clientes e familiares; investigação do prontuário; pesquisa nos grupos de convergência (os próprios EMs), através de gravações, e também de observações feitas por uma auxiliar de pesquisa no momento do EM; e auto-observação.

Os EMs se iniciavam com apresentação dos participantes, seguida pela escolha das músicas 
pelos sujeitos. Essas músicas eram tocadas e cantadas pela enfermeira e/ou por um músico que também fazia parte da equipe de pesquisa, além de cantadas pelos participantes do grupo. Após a execução musical os participantes falavam sobre as músicas, o que estimulou narrativas de suas vivências relacionadas à música e ao seu cotidiano, promovendo o compartilhamento de experiências e o diálogo grupal. Ao final era realizada uma avaliação da atividade desenvolvida.

Para atingir os objetivos desse recorte da pesquisa, os dados enfocados foram os discursos dos sujeitos referentes à avaliação da estratégia. Essa etapa avaliativa foi prevista, desde o início do projeto, como um importante ponto de convergência entre a prática assistencial e a pesquisa, e acabou por tornar-se um espaço de reflexão ao final de cada encontro desenvolvido, momento em que os participantes podiam falar sobre o ocorrido, expressando suas impressões, opiniões, sentimentos e ainda sugerindo mudanças, quando julgavam necessário.

Os grupos desenvolveram-se na sala comunitária em que é realizada a quimioterapia, no Hospital-Dia de um hospital militar na cidade do Rio de Janeiro. Foram realizados oito EMs, desenvolvidos semanalmente em dia fixo, com a duração de aproximadamente uma hora.

Os sujeitos foram clientes e familiares que participaram de pelo menos um encontro musical, num total de 27 sujeitos, sendo 17 clientes e 10 familiares, de ambos os sexos e idades variadas. O critério de inclusão do sujeito era seu desejo de participar e sua inserção no tratamento de quimioterapia, independente do estadiamento do câncer e do ciclo da quimioterapia, ou mesmo se estavam acompanhados por familiares ou não. Os familiares participantes eram todos acompanhantes dos clientes em tratamento, e embora uma dessas clientes não pudesse participar do grupo devido à sua condição clínica, sua acompanhante solicitou participar e foi incluída entre os sujeitos.

O discurso produzido pelos sujeitos nos EMs foi analisado de acordo com a proposta de análise do discurso, visto que esta trabalha com o processo de constituição dos sujeitos e dos sentidos. Essa análise não se restringe ao conteúdo, mas também à forma como o sujeito faz sua enunciação, o que amplia a compreensão acerca do fenômeno estudado. ${ }^{11}$

Essa pesquisa foi aprovada pelo Comitê de Ética em Pesquisa da Escola de Enfermagem Anna Nery da Universidade Federal do Rio de Janeiro, com o protocolo de $n^{\circ}$ 068/09, sendo respeitados os aspectos éticos da pesquisa, conforme o disposto na Resolução 196/96 do CNS/MS, tendo os participantes assinado o Termo de Consentimento Livre e Esclarecido. Os sujeitos tiveram seu anonimato mantido, sendo identificados por letras e números, conforme a descrição que se segue: Cliente $=\mathrm{C}$ e Familiar = F, acrescidos das letras M (Masculino) e $\mathrm{F}$ (Feminino), sendo seguidos por um número que indica a ordem de inserção nos EMs. No processo de análise ainda foram acrescentados o número do EMs, em alusão ao trecho de análise correspondente (Ex: EM4 se refere ao $4^{\circ}$ encontro). Assim, a identificação CF3-EM4 se refere à cliente do sexo feminino que foi a terceira pessoa inserida nos encontros, e o trecho analisado se refere ao $4^{\circ} \mathrm{EM}$.

\section{RESULTADOS E DISCUSSÃO}

Os resultados aqui apresentados foram fundamentados na avaliação dos participantes, pois por mais abrangentes que sejam as observações acerca do fenômeno sob análise, ainda se caracterizam como reducionistas ao se basear somente na ótica do observador. Deste modo, em consonância com a direção teórico-metodológica deste estudo, a própria avaliação dos clientes e familiares participantes, sobre a estratégia de cuidado, constituiu-se como uma importante fonte de dados. Ou seja, não foi somente mais uma etapa da metodologia, mas também uma atitude ética voltada para o cuidado, pois é importante estar atento para o sistema de referências e significados dos participantes do processo de ensinar-aprender neste contexto.? Assim, no âmbito dos EMs, os partícipes do cuidado, clientes, familiares e enfermeira facilitadora puderam ampliar o conhecimento de si e do outro, não só durante o desenvolvimento do encontro, mas também no momento da avaliação.

A possibilidade de poder avaliar e sugerir mudanças nos encontros, também foi uma forma de construção de autonomia, pois explorou a experiência pessoal, promoveu a autoconsciência e estimulou a capacidade de escolha. ${ }^{12}$ Destaca-se que a própria avaliação também pode subverter o instituído, pois no ambiente hospitalar frequentemente o cliente é objeto, e não sujeito do seu cuidado.

Ao valer-se da condição de sujeitos partícipes do cuidado, os participantes co-construiram um espaço de afirmação de vida. Isto porque, a participação em estratégias grupais de cuidado pode proporcionar sensação de pertencimento, conhecimento das emoções, percepção da vida como tendo significado, e o desenvolvimento da consciência, o que amplia a qualidade de vida do cliente oncológico. ${ }^{8}$ 


\section{Influência da música no processo terapêutico}

A análise dos dados apontou diversos benefícios promovidos pela música no âmbito dos EMs, contudo, nesse recorte, apontaremos os que tiveram mais importância na ótica dos sujeitos.

Uma das participantes que mais demonstrou ter se beneficiado com os EMs, disse durante a avaliação no $4^{\circ}$ EM: para mim é sempre muito bom! E as músicas ótimas, reconfortantes (CF10-EM4). Nesse encontro, ela relacionou as músicas cantadas, católicas, em sua maioria, ao conforto que sentiu, ligado com sua crença religiosa. Seu discurso ratifica a importância das músicas em contextos terapêuticos partirem da preferência dos participantes. Nos EMs, alguns sujeitos escolheram músicas religiosas, e o canto grupal destas mobilizou os participantes em diversos momentos, contribuindo para a expressão das suas crenças. Respeitar a escolha do cliente, relacionada à sua identidade musical, que inclui a vivência religiosa, pode promover bem-estar e conforto. ${ }^{13}$

É importante a enfermeira perceber que a mente racional e a ciência moderna não têm todas as respostas para as condições humanas que enfrenta. Isso requer que ela esteja aberta ao desconhecido, ao mundo subjetivo das próprias experiências e as dos outros, que são afetadas por muitos fatores que não podem ser explicados totalmente. ${ }^{7}$ Significa ter sensibilidade para as manifestações religiosas dos clientes e familiares, mesmo que estas não façam parte de suas próprias crenças. $\mathrm{Ou}$ seja, estar aberto é mais do que respeitar a crença religiosa do outro, é perceber as possibilidades desta contribuir para a sua reconstituição.

Outra cliente avaliou os EMs, ao final de sua terceira participação, através de discurso polissêmico: ajuda! Ajuda com certeza, porque com a música a gente vai se soltando. De repente, a pessoa está quieta e uma passagem da música já... distrai, surge um assunto, e uma fala, a outra fala, e já vai tendo conhecimento uma com a outra. Realmente é muito bom (CF3-EM7).

Seu discurso associa inicialmente a influência da música à sua mudança de atitude, reservada e pouco comunicativa com o grupo no $1^{\circ} \mathrm{EM}$, mas que gradualmente se modificou, pois foi se soltando e deixou de 'estar quieta'. Em seguida ela se refere à outra influência benéfica da música, a distração do que a afligia, revelado na entrevista individual quando do surgimento do câncer, seguido do início da quimioterapia à época de sua aposentadoria, momento em que, segundo ela, alimentava perspectivas positivas de mudança de vida, e da tristeza sentida diante da situação difícil pela qual passava.
Este é um dos processos pelo qual a música revelou seu potencial terapêutico nos EMs: ajudar a 'distrair' das situações angustiantes relacionadas com o adoecimento e tratamento do câncer. Vale destacar que outros estudos também salientam os benefícios trazidos pelas atividades musicais aos clientes durante o tratamento oncológico, à exemplo da sensação de relaxamento. Este efeito causa uma mudança de foco dos problemas gerados pelo câncer, para as boas lembranças relacionadas às músicas escutadas. ${ }^{14}$

Outra cliente, após quatro participações seguidas, nos EMs 4, 5, 6 e 7, avalia a mudança que ocorreu a partir dessa convivência mais frequente: eu acho que cada dia está melhor porque parece que a gente vai se sentindo mais à vontade. Vai... entendeu? $E$, porque no primeiro dia a gente ficava assim... [fala baixinho]. É a música, é... [volta a falar alto]. Agora não, está todo mundo mais à vontade. É assim, é... [usando a comunicação não verbal através de gestos, para demonstrar a sua percepção sobre a evolução de comportamentos no grupo] (CF14-EM7).

Sua avaliação é singular, no sentido de apontar a possibilidade de evolução que o processo continuado de participação nos EMs pôde proporcionar. Isto é, a cada dia ficava melhor, porque podiam estar 'mais à vontade', e ela exemplifica isso através de teatralização, mostrando que no primeiro contato no grupo, as pessoas ainda se sentiam desconfortáveis, possivelmente inseguras, e falavam em um tom de voz baixo. Em seguida fala 'a música é...' , o seu não-dito é substituído pelo elevar da voz, ao dizer que está 'todo mundo mais à vontade', relacionando a música com a descontração grupal. Seu discurso teatralizado provocou um momento lúdico entre as pessoas que riram e demonstraram concordar com sua opinião.

Sua avaliação indica que a participação regular e frequente nos EMs contribuiu com o desenvolvimento da empatia e familiaridade entre os participantes, além de proporcionar novas experiências, também apontado por CF3-EM7. Ressalta-se que uma das possibilidades terapêuticas da música é o fato de que, a partir de uma experiência musical, pode-se alcançar outras experiências verbais ou corporais que permitem expressões de temas no contexto em que ocorrem. ${ }^{8}$

A partir das avaliações dos participantes, é possível constatar que os EMs produziram diversas influências benéficas interligadas entre si, como aponta outra cliente: pra mim foi maravilhoso! Porque a hora passa rápido com a música, conversa... Só tenho a dizer isso: ótimo! O encontro foi maravilhoso e deve 
ser repetido com outras pessoas... e a gente fica mais integrada com as pessoas [...] uma higiene mental! Para mim foi maravilhoso, e para as pessoas novas, que vão estar aqui, que vocês façam isso sempre. Voltem sempre para cantar para a gente, né? Só isso! (CF16-EM8).

A avaliação, em forma de síntese, proporcionada pelo seu discurso, revelou diversos aspectos viabilizados pelo processo terapêutico implementado: distração proporcionada pela música e a conversa, integração com os outros participantes e higiene mental, aqui colocada no sentido de aliviar as tensões e preocupações relacionadas à família, à doença e ao contexto quimioterápico, referidas por ela durante esse encontro.

A efetividade da estratégia de cuidado na aliança do recurso musical com o diálogo, promovido no encontro da enfermeira com os sistemas familiares, foi ainda validada por outro cliente que participou de cinco encontros: Porque a gente conversa, troca ideia, depois vem a música e alegra ainda mais o ambiente. É por aí (CM6-EM7). Sua avaliação aponta outra interessante relação entre a música e a alegria, aproximando seu discurso ao de outros participantes que apontaram a relação entre música e descontração. O uso da palavra 'alegria' desperta para a importância do humor para CM6, expresso por elesobdiversas formas duranteos encontros, através de brincadeiras com outros participantes, que promoveram acolhimento para com os que iniciavam o tratamento de quimioterapia e que demonstravam medo ou ansiedade com a situação. Bem-humorado e alegre, ele co-construiu com os demais partícipes do cuidado um ambiente propício para a reconstituição.

Ele ainda aponta também a importância da descontração para distrair e desviar o foco para pensamentos mais agradáveis: eu acho que é muito importante pela descontração que traz no ambiente... porque afinal de conta a gente está aqui e está com a cabeça meio... né? E esse encontro, eu acho que... distrai e leva a gente para um outro pensamento... eu acho muito bacana isso. Muito bacana mesmo (CM6-EM7). Aqui surge uma outra forma de se identificar a modificação que ocorre na participação dos encontros: 'leva para um outro pensamento'. O que se destaca aqui é que com o relaxamento, distração, descontração, é possível pensar de outra forma, muda-se a perspectiva, saindo do foco da doença para o da saúde, do cotidiano. Essa possibilidade terapêutica da música, relacionada com a distração e resgate de boas lembranças, é também apontada em estudo com clientes que participaram de visitas musicais durante a hospitalização. ${ }^{13}$

Há pontos de contato entre a avaliação de CM6 e a de sua esposa, também relacionada às narrativas e à música: distrai, conta histórias, cada um cantou (FF6-EM2). Seu discurso polissêmico aponta diversos aspectos dos EMs, iniciado pela distração, e em seguida com 'conta histórias', que é uma outra forma de ver as narrativas sobre experiências de vida que ocorreram no $2^{\circ} \mathrm{EM}$. No final do discurso, se refere à música, e, apesar de demonstrar sua preferência pela expressão verbal, também mostrou prazer em cantar junto com os outros.

Outra participante também se refere à relação entre narrativa e música, ao mencionar que se sentiu mais à vontade para falar da família no $3^{\circ}$ EM: porque... falar da família é muito bom também... e a oportunidade da gente falar. A música... ajuda (CF8-EM3). Seu discurso sinaliza que a oportunidade de falar esteve implicitamente vinculada ao espaço de conversação que se configurou no desenvolvimento dos encontros, estimulado pela música. Em outros momentos de seu discurso, ela revelou a dificuldade de falar sobre o adoecimento ou o tratamento, às pessoas em geral, e, principalmente em relação aos seus familiares mais próximos.

É importante destacar que a música não promove somente distração, nem se configura como 'fuga da realidade', mas também contribui com a reflexão sobre o adoecimento sobre o câncer. Esse aspecto tem relações com outro estudo sobre adolescentes com câncer que passaram pelo processo de musicoterapia. A pesquisa apontou que a utilização da música contribuiu com que os adolescentes fizessem uma reavaliação positiva de sua situação, e promoveu a expressão emocional e apoio social. Concluiu-se que a música emergiu como um potente canal de comunicação e expressão dos sofrimentos, dando-lhes outros sentidos e significados, e auxiliando-os a enfrentar o estresse do adoecimento. ${ }^{15}$

As dificuldades para encontrar interlocutores que estejam dispostos a conversar sobre temas tão difíceis indicam a necessidade de criação de espaços de apoio aos clientes. Estudo desenvolvido com grupos de mulheres com câncer demonstrou que a convivência entre estas mulheres configurou-se no ponto chave para a reabilitação das mesmas. Elas referiram a importância de um espaço para esclarecimentos de eventuais dúvidas e para a integração, como forma de promover lazer e equilíbrio. Outra questão interessante é que nas atividades de apoio sempre havia um componente educativo. Isto aponta a inter-relação entre a aquisição de informações, a percepção de si e a possibilidade de expressar-se para promover a redução 
do medo, da insegurança e da ansiedade além de contribuir com o desenvolvimento do potencial de saúde do paciente e da família. ${ }^{16}$

Esse potencial terapêutico do EM para a família foi abordada por uma familiar acompanhante, que se mostrou mais reservada no início dos encontros, mas foi se desinibindo aos poucos e durante a avaliação fez menção à descontração: ah, com certeza![...] É o que ela falou, ajuda a gente a levar mais fácil. Descontrai. Ajuda a passar o tempo mais rápido também. Faz diferença (FF3-EM7). Seu discurso metafórico 'levar mais fácil' tem o não-dito implícito de que há algo difícil, que podemos inferir que é o adoecimento e mais especificamente, a quimioterapia. A situação vivida pelo doente, sob tratamento, afeta e é afetada por todos os familiares; estes, também sentem como se eles próprios o estivessem realizando. ${ }^{3}$

Ao pensar no potencial terapêutico na perspectiva dos sistemas familiares, é importante destacar que os próprios familiares acompanhantes se beneficiaram da participação nos EMs, como a maioria (8) referiu em suas avaliações, apontando os seguintes aspectos: o tempo passa mais rápido; as pessoas se apresentam mais descontraídas; as músicas as distraem, as relaxam, e elas se sentem mais à vontade para falar; aumenta a possibilidade de interação e trocas entre as pessoas.

Outro aspecto importante se refere à modificação do humor, revelado no discurso metafórico de uma cliente durante a avaliação: não, hoje eu estou de farol baixo. Não sou de falar muito não [dá risada quando alguém comenta que o 'farol melhorou']. É, até que melhorou um pouquinho. Eu melhoro depois que vocês vêm. Melhoro sim, mesmo quando eu estou assim meio para baixo eu melhoro (CF14-EM6). Ela usou o termo 'farol baixo' para designar o rebaixamento do humor, nesse dia relacionado a um estado gripal que a deixou prostrada. Mesmo assim, ela considerou que seu ânimo melhorou com a presença da enfermeira/facilitadora e do músico acompanhante durante os EMs.

Outro cliente também apontou em sua avaliação a característica do EM relacionada à alteração do humor: continuar, uma higiene mental para a gente. Um ânimo a mais... principalmente para mim que estou precisando, né? [...] Ah, um bom astral. (CM9-EM8). Nesse trecho ele se refere à prostração que sentia nesse dia, devido à QT, mas com a lembrança do encontro anterior, no qual esteve ativamente envolvido, e no qual teve um 'bom astral', que é um termo que podemos relacionar à energia positiva circulante no grupo.
Essa concepção acerca dos EMs é ratificada por outra participante, em sua avaliação: estou achando ótimo. Gostei muito, estou achando as pessoas bem alegres, bem simpáticas. Isso também faz com que ficamos animadas. Alegra os que estão caídos, tristes, como eu às vezes estou (CF15-EM4). Ela relacionou seu ânimo às pessoas alegres e simpáticas do grupo, que certamente lhe passaram uma energia positiva. Mas o interessante é que a mais animada nesse dia foi ela própria, que contagiou os outros com sua positividade e animação.

Dessa forma, o ânimo a que se referem está relacionado ao bem-estar, à alteração da própria condição de prostração relacionada a condições clínicas ou psicológicas, apontando as possibilidades terapêuticas dos EMs, voltadas para restaurar a integralidade do sujeito. O propósito de um ambiente de reconstituição relaciona-se também com a harmonia e o uso de modalidades de cuidar-reconstituir relacionada à música e relaxamento, entre outros. ${ }^{17}$

$\mathrm{Na}$ área da oncologia há estudos que reportam diferentes atividades, como trabalhos em grupo e técnicas de relaxamento, distração e imaginação dirigida, que auxiliam o paciente a refletir sobre a influência da doença em sua vida, aprender estratégias de enfrentamento e estabelecer metas. ${ }^{2}$ É importante discutir a criação de espaços alternativos que atendam o sistema familiar (con)vivendo com câncer em sua integralidade. Assim, deve-se interligar recursos criativos/artísticos com toda a forma de conhecimento e múltiplas maneiras de ser como parte do processo de cuidar.?

Assim, de acordo com os sujeitos, ficou evidenciado que a música foi um importante elemento para promover o cuidado no âmbito dos EMs, pois trouxe conforto espiritual, bem estar, relaxamento, redução do estresse, estimulou a comunicação e melhorou o humor dos participantes.

\section{Influência das narrativas no processo terapêutico}

A descontração promovida pela música desenvolveu um ambiente propício ao desenvolvimento da expressão verbal, promovendo uma conversação terapêutica que explorou o diálogo e o entrecruzamento de idéias, o que produziu conhecimento e novos sentidos para os participantes.

No momento da avaliação no $3^{\circ} \mathrm{EM}$, um cliente apontou a importância dessa conversação, visto que costuma falar pouco: muito bom! Até eu falei! Quando lhe questionei o porquê, ele respondeu: é porque apareceu o tema... talvez tenha sido isso 
[...]. Falar a gente fala, mas não é a todo o momento, a toda a hora [...] (CM6-EM3). Sua afirmação sobre a fala estar condicionada ao tema e à ocasião indica a importância de se desenvolver um ambiente de cuidado capaz de propiciar o desenvolvimento a expressão verbal, o que ratifica a contribuição dos EMs como campo de possibilidades, aí incluída a promoção de conversação terapêutica entre os sujeitos. Uma conversação terapêutica explora o diálogo e o entrecruzamento de ideias, produzindo novos sentidos para os participantes. ${ }^{18}$

No $3^{\circ} \mathrm{EM}$, bastante focado na conversação sobre relações familiares, a avaliação de uma familiar também trouxe para o espaço grupal a importância do diálogo na construção de uma rede de apoio: é melhor porque as pessoas interagem... porque tem coisas que a gente pensa que só acontece com a gente, e quando a gente está conversando, interagindo, você vê que... e tem a capacidade de ir melhorando, o convívio com a família, um apoiando o outro. Acho também isso muito legal, e no diálogo você percebe que um começa a se apoiar no outro. Um dia eu estou passando mal, depois eu estou melhor, um dia está de uma forma e na outra vai estar melhor ainda. Isso aqui é importante, ajuda muito (FF8-EM3).

Seu discurso aponta a possibilidade de interagir a partir da conversação, e de como isso afeta positivamente a percepção de que sua experiência não é única e pode ser partilhada. Essa percepção relaciona-se com algumas premissas sobre narrativa, das quais destacam-se: os sistemas humanos são geradores de linguagem e de sentido, a comunicação e o discurso definem a organização social. Todos os sistemas humanos são sistemas linguísticos melhor descritos por aqueles que participam deles e não por observadores externos 'objetivos' ${ }^{18}$ Assim, os EMs podem ser considerados como um sistema lingüístico, no qual os participantes puderam se comunicar e produzir sentidos, organizando com as músicas e narrativas sua forma de se expressar e se relacionar. É, sobretudo, um sistema terapêutico de cuidado, pois essa organização tinha a finalidade de atender às necessidades individuais e coletivas dos participantes.

Uma questão de destaque ainda no discurso de FF8-EM3, se refere a 'um se apoiar no outro', apontando outra importante função do processo grupal, que é o de formar uma rede de apoio. Os processos de rede se dão no espaço interpessoal, pois a rede social contém e é gerada pelas histórias que constituem a identidade de seus membros, legitimando a posição relativa dos participantes e gerando a existência simbólica destes membros. ${ }^{19}$
Nesse contexto, os EMs se constituíram como rede social através das narrativas das histórias de vida, experiências e crenças que, por um lado, legitimaram sua vivência com o contexto do câncer e da quimioterapia, e, por outro, legitimaram sua reafirmação perante a vida a partir das músicas e das atitudes positivas de enfrentamento.

No processo avaliativo, uma das clientes que mais se expressou através da narrativa, surpreendeu-se com sua prolixidade: difícil [falar sobre si], mas aqui não, aqui eu participei. Porque aqui estão todos no mesmo... navio, né? Depois ela retifica seu discurso metafórico: no mesmo barco, então tem que passar isso para os novos também. Foi maravilhoso! [...] O que eu tinha vontade... não sou de falar não [...]. Mas eu não sou de falar... mas aqui? Não sei se é porque estamos todos juntos, né?(CF16-EM8).

Seu discurso expressa identificação com os outros participantes, revelada nas afirmações: 'estarem todos no mesmo barco', e mais adiante, 'estamos todos juntos'. Esse sentimento de pertencimento é muito importante na formação de processos terapêuticos grupais, e pode originar-se do ato de compartilhar com outras pessoas que vivenciam experiências semelhantes, criando a possibilidade de troca e crescimento mútuos. $\mathrm{O}$ grupo de apoio mostra-se relevante para a troca de afeto, compreensão e ajuda, o que promove satisfação nas relações e suporte emocional positivo. ${ }^{20}$

Outra cliente, que participou quatro vezes dos encontros, reafirma a importância da conversação terapêutica: acrescenta muito, muito [os EMs]! Porque quando a gente está aqui, por mais que a gente converse, é uma coisa [referindo-se à sala comunitária da quimioterapia]. E aqui, não. Porque aqui... um entra em contato com o outro, e todos acabam no final... Entendeu? Acabam um ajudando o outro assim... conversando... cantando, e faz muita diferença. A gente sai daqui com outra cabeça. Porque quando a gente sai sem o nosso encontro [musical], a gente sai quieto, vai... e por mais que a gente tenha uma cabeça feita, como diz a minha filha, mas a gente não sai com a cabeça... Não é? A cabeça fica assim... mais tranquila. Bota pra fora muita coisa, cantando... entendeu? (CF14-EM7).

Nesse fragmento discursivo, esta cliente apontou dois aspectos importantes. O primeiro relativo ao espaço: a conversa que se estabelece no EM se diferencia de outras que ocorrem no setor. O outro aspecto apontado no seu discurso metafórico diz respeito aos efeitos produzidos: "sai com outra cabeça"; "bota pra fora quando canta", interligando dois tipos de expressão, avaliados como benéficos por ela: os diálogos e o canto coletivo. 
Nesse sentido, ainda que clientes e familiares mantenham um clima interativo com outras pessoas que vivenciam situações semelhantes de adoecimento, é necessária a intencionalidade de cuidar por parte da enfermeira na promoção de um ambiente de sustentação baseado na relação de ajuda-confiança, mobilizador da interação social e potencializador das forças internas dos sujeitos..$^{21 ; 7}$

Esse papel potencializador dos EMs foi apontado por CF16 em sua avaliação: [...] aprende-se mais [...] que estamos todos no mesmo barco, deve-se ter esperança e fé para sair daqui... sair curado. É o que eu levo daqui sempre (CF16-EM6). Na sua perspectiva, a participante refere a possibilidade de aprendizagem com a convivência do grupo, apontando ainda dois pontos importantes para processos grupais em oncologia, o sentimento de pertencimento ao grupo, que facilita o compartilhamento de conhecimentos e experiências, e a fé e a esperança, fundamentais para a sua capacidade de enfrentamento da doença.

Outra participante também se refere à esperança em sua avaliação: seu trabalho é muito interessante! [...] Sempre pra melhor. Mais união, mais descontração, e se formam amizades! Por nós termos o nosso problema, não quer dizer que a gente não possa fazer uma amizade boa, não é? Eu acho que o seu trabalho é muito importante! Muito importante! E deve ser levado a todos os hospitais, a todos os doentes, eu acho que é muito bom. Valeu, que Deus te abençoe, lutando sempre pra melhor, crescer, crescer...[...] Vai dando mais esperança (CF10-EM7). Ela se refere tanto à amizade, que ela encontrou no grupo, quanto à esperança, o que permite uma aproximação entre o afeto recebido e partilhado no grupo e o sentimento de esperança, muito importante na situação vivenciada pelos participantes.

Seu empenho em desejar o crescimento da enfermeira/facilitadora, traz reflexões acerca das possibilidades de evolução para todos os participantes, inclusive da própria enfermeira, através do contato grupal ao partilhar experiências tão significativas através das músicas, narrativas e das atitudes de cuidado que a maioria dos sujeitos demonstrou uns com os outros. Na busca de seu próprio desenvolvimento é necessário que a enfermeira aprofunde a autoconsciência, procurando ir além de si mesma na procura por novos caminhos para promover o cuidado. ${ }^{7}$

No processo de avaliação os participantes apontaram que a distração ao mesmo tempo promove o relaxamento e reduz o estresse relacionado ao contexto da quimioterapia, permitindo que os participantes se expressem livremente sobre os assuntos de seu interesse relacionados ao processo de viver, seja a própria música, histórias do cotidiano e do passado, suas próprias crenças, ou mesmo brincadeiras sobre o processo grupal. $\mathrm{O}$ que não invalida que, em alguns momentos, falassem sobre seu processo de adoecimento e tratamento, temas que certamente os cercam constantemente. O que estava implícito na dinâmica dos encontros era que podiam falar sobre a doença e depois retomar os outros temas que os aproximavam de aspectos mais lúdicos e saudáveis da convivência social, exercendo assim a autonomia na escolha do que era melhor para si naquele momento.

Dessa forma, na ótica dos participantes, as narrativas surgidas no desenvolvimento dos EMs contribuíram para o cuidado ao promover interação, melhorar o convívio familiar, estimular a participação ativa dos sujeitos, estabelecer relações de ajuda, reduzir a ansiedade, e promover esperança e fé.

\section{CONSIDERAÇÕES FINAIS}

O desenvolvimento dos EMs relacionou-se ao uso de modalidades de cuidar-reconstituir ligadas à música e ao relaxamento, entre outras formas de expressão artística, além de considerar que a sustentação da relação de ajuda-confiança criou um campo de energia positiva que afetou aos participantes. A participação nos encontros proporcionou a sensação de pertencimento, reconhecimento das emoções, percepção da vida como tendo significado, e o desenvolvimento da consciência, o que possibilitou a ampliação da qualidade de vida do cliente oncológico e seus familiares. Dessa forma, conclui-se que o EM promoveu um verdadeiro encontro entre os partícipes do cuidado, clientes, familiares e enfermeira, mobilizando um ambiente de reconstituição no contexto da quimioterapia.

Esse estudo aponta a importância de serem desenvolvidas estratégias de cuidar/reconstituir no âmbito da quimioterapia, visando implementar a assistência integral e humanizada preconizada pelo Ministério da Saúde, que atenda à complexidade do sistema familiar que (con)vive com a situação do câncer.

Destaca-se assim a contribuição dos EMs como uma nova forma de abordagem grupal que pode promover o cuidado integral aos clientes e familiares em tratamento oncológico. Sugere-se que esta estratégia de cuidado seja investigada em outros contextos assistenciais voltadas para doenças crônicas, pois as suas múltiplas possibilidades 
expressivas contribuem para o conhecimento da enfermagem acerca das condições e necessidades tanto dos clientes quanto dos familiares, além de facilitar a comunicação e interação cliente/familiar/enfermagem.

Os EMs, fundamentados na abordagem transdisciplinar entre a enfermagem e musicoterapia, contribuíram para o desenvolvimento de um ambiente mobilizador da interação social e potencializador de recursos para o enfrentamento da doença. Essa abordagem ampliou os recursos que permitiram a implementação dos encontros como uma estratégia de cuidado expressivo e integrador, amparada em uma atitude ética voltada para a co-construção de um ambiente de cuidado com os sujeitos. Esta perspectiva insere os EMs no âmbito dos cuidados fundamentais que sustentam a ciência e a arte da enfermagem, podendo contribuir com a criação de estratégias assistenciais em outros contextos.

\section{REFERÊNCIAS}

1. Brasil. A situação do câncer no Brasil. Ministério da Saúde, Secretaria de Atenção à Saúde, Instituto Nacional de Câncer, Coordenação de Prevenção e Vigilância. Rio de Janeiro (RJ): INCA; 2006.

2. Secoli SR, Padilha KG, Oliveira Leite RC. Avanços tecnológicos em oncologia: reflexões para a prática de enfermagem. Rev Bras Cancerologia. 2005 OutDez; 51(4):331-7.

3. Souza MGG, Espírito Santo FH. O olhar que olha o outro... um estudo com familiares de pessoas em quimioterapia antineoplásica. Rev Bras Cancerologia. 2008 Jan-Mar; 54(1):31-41.

4. Wernet M, Ângelo M. Mobilizando-se para a família: dando um novo sentido à família e ao cuidar. Rev Esc Enferm USP. 2003 Mar; 37(1):19-25.

5. Bergold LB. Encontro musical: uma estratégia de cuidado de enfermagem junto a sistemas familiares no contexto da quimioterapia [tese]. Rio de Janeiro (RJ): Escola de Enfermagem Anna Nery/UFRJ; 2009.

6. Morin E. A cabeça bem-feita: repensar a reforma, reformar o pensamento. Rio de Janeiro (RJ): Bertrand Brasil; 2006.

7. Watson J. Nursing: the philosophy and science of caring. Colorado (US): University Press of Colorado; 2008.

8. Ruud E. Music therapy: improvisation, communication and culture. Barcelona (ES): Publisher; 1998.
9. Trentini M, Paim L. Pesquisa convergente-assistencial: um desenho que une o fazer e o pensar na prática assistencial em saúde-enfermagem. Florianópolis (SC): Insular; 2004.

10. Trentini M, Paim L. An innovative approach to promote a healthy lifestyle for persons with chronic conditions in Brazil. In: Turley AB, Hofmann GC. Life style and health research progress. New York (US): Nova Science Publishers; 2008.

11. Orlandi EP, Análise de discurso: princípios e procedimentos. $4^{\mathrm{a}}$ ed. Campinas (SP): Pontes; 2003.

12. Morin E. O método 5: a humanidade da humanidade. Porto Alegre (RS): Sulina; 2002.

13. Bergold LB. A visita musical como estratégia terapêutica no contexto hospitalar e seus nexos com a enfermagem fundamental [dissertação]. Rio de Janeiro (RJ): Universidade Federal do Rio de Janeiro, Escola de Enfermagem Anna Nery; 2005.

14. Chagas M, Gazaneo L, Aguiar M. Projeto encanto: avaliando uma proposta de humanização hospitalar. In: Anais do $5^{\circ}$ Encontro Nacional de Pesquisa em Musicoterapia. [CD-ROM] Rio de Janeiro: CBM/ CEU; 2004.

15. Silva FO, Craveiro de Sá L. Musicoterapia e o desenvolvimento de estratégias de enfrentamento ao estresse de adolescentes portadores de câncer. In: Anais do $8^{\circ}$ Encontro Nacional de Pesquisa em Musicoterapia. [CD-ROM] Rio de Janeiro: CBM/ CEU; 2008.

16. Fernandes AF, Rodrigues MS, Cavalcanti PP. Comportamento da mulher mastectomizada frente às atividades grupais. Rev Bras Enferm. 2004 JanFev; 57(1):31-4.

17. Watson J. Watsons theory of human caring and subjective living experiences: carative factors/ caritas processes as a disciplinary guide to the professional nursing practice. Texto Contexto Enferm. 2007 Jan-Mar; 16(1):129-35.

18. Goolishian H, Anderson H. Narrativa e self: alguns dilemas pós-modernos da psicoterapia. In: Schinitman D. Novos paradigmas, cultura e subjetividade. Porto Alegre (RS): Artmed; 1996.

19. Sluzki CE. A rede social na prática sistêmica: alternativas terapêuticas. São Paulo (SP): Casa do Psicólogo; 1997.

20. Rodrigues DP, Silva RM, Fernandes AFC. O processo adaptativo de mulheres mastectomizadas: Grupo de apoio. Rev Enferm UERJ. 2003 Jan-Abril; 11(1):64-9.

21. Watson J. Enfermagem pós-moderna e futura: um novo paradigma da enfermagem. Loures (PT): Lusociência; 2002. 